\title{
Investigation of school building microclimate using advanced energy equipment: Case study
}

\author{
Mamdooh Alwetaishi ${ }^{1+}$, Ali Alzaed ${ }^{1}$, Giulia Sonetti ${ }^{2}$, Raid Shrahily ${ }^{3}$, Latif Jalil ${ }^{4}$ \\ ${ }^{1}$ Department of Civil Engineering, College of Engineering, Taif University, Taif 21974, Saudi Arabia \\ ${ }^{2}$ Department of Regional \& Urban Studies and Planning Politecnico di Torino and University di Torino, Turin 2410129, Italy \\ ${ }^{3}$ School of Architecture, Design and Built Environment, Nottingham Trent University, Nottingham NG11 8NS, UK \\ ${ }^{4}$ CSM Billing Ltd Company, Head for Research and Development, London NW4 3XA, UK
}

\begin{abstract}
Buildings are responsible of major energy consumption globally. In addition, they are linked to thermal comfort. The need to provide comfort becomes more crucial in schools as they are the place where students learn, and develop their skills. This research aims to investigate the energy responsiveness of new and traditional school building design, where major variation in form, amount of external walls and glazing are different. The research focused on indoor microclimate condition of selected schools in the city of Jeddah where the climate is hot and humid using advanced tools for monitoring. The research uses advanced energy equipment to measure several aspects such as floor temperature, roof temperature, globe temperature and other factors which can lead to predictable thermal comfort of users. The findings suggest that a larger area of glazing shielded from sunlight has a greater influence on both indoor condition and general thermal sensation. The finding also suggests that the glazing ratio is a major contributor on indoor thermal pattern which can result in an increase in temperature profile between from $7-10^{\circ} \mathrm{C}$. The findings of this research can assist in the improvement in the design of the prototype school building in hot and humid climate.
\end{abstract}

Keywords: Energy conservation in buildings, Microclimate investigation, School buildings, Thermal comfort

\section{Introduction}

One of the most important purposes of buildings is to provide comfort for users, regardless of the type of building. Designers, engineers and other specialist have expressed an increasing concern with regards to thermal comfort and internal energy in buildings.

Most researches have been conducted in domestic and commercial buildings including offices; however very little studies have been carried in educational buildings and schools in particular. The lack of this knowledge in Saudi Arabia is much greater to the extent that there is very limited published research about school buildings in Saudi Arabia. The lack of published work to school buildings with regard to thermal comfort and building performance has a great impact on the users, who are students, and can have an impact on their productivity achievements. Saudi Arabia has a total of fourteen prototype school building designs, in total there are 14 designs. Any fault in the design will be replicated many times, in a study conducted by Sojobi et al. [1], which investigate the climate change in Lagos state, Nigeria.

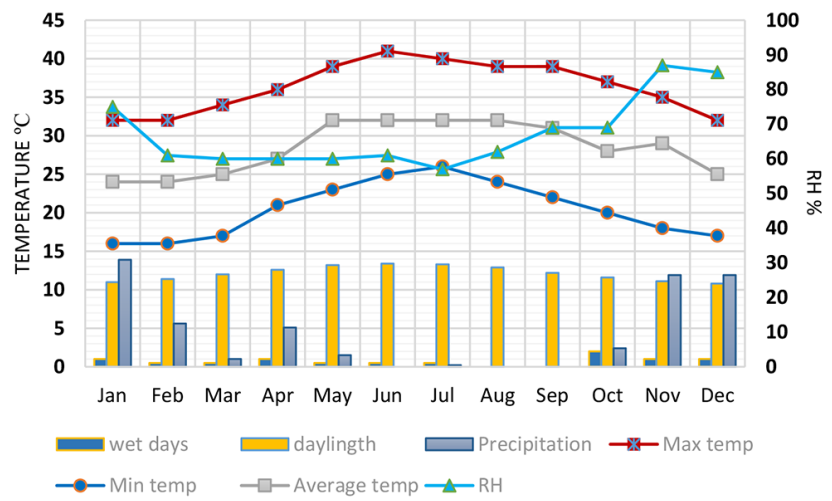

Fig. 1. Climate of Jeddah city. Hot and humid.

(reproduced from: http://www.jeddah.climatemps.com/)
This is an Open Access article distributed under the terms of the Creative Commons Attribution Non-Commercial License (http://creativecommons.org/licenses/by-nc/3.0/) which permits unrestricted non-commercial use, distribution, and reproduction in any medium, provided the original work is properly cited.

Copyright (C) 2018 Korean Society of Environmental Engineers
Received January 23, 2017 Accepted June 27, 2017

${ }^{\dagger}$ Corresponding author

Email: Alwetaishi.mamdooh@hotmail.com

Tel: +966-12-727-2020 Fax: +966-12-727-4299 
Various studies have demonstrated the importance of climate and microclimatic studies and their influencing factors, variabilities and interactions Sojobi et al. [1]; Deng et al. [2]. The study indicated that the persistent state of minimum temperature often precedes the arrival and reversal of the phase of the maximum temperature. There is a strong correlation between microclimate permeants and thermal comfort, as the latter is effected by microclimate elements which include air temperature, wind speed, relative humidity and solar radiation [2]. Aspects of microclimate are differ from place to another, however, considering the building indoor elements it is important to consider the list mentioned related to thermal comfort which influence user sensation.

\subsection{Background to Study}

Oriented buildings could be perhaps the most cost effective approach in respect to passive solar design in achieving thermal comfort, as it comes at a very early design stage of buildings and it does not require any mechanical equipment [3]. Bekkouche [4] and Hamdani [5] have expressed that it is in the main principle of architectural design requirement to orientate the house in the right direction.

In harsh climate regions, where the temperature varies dramatically, orientation of buildings are prime importance [4], Aseem [6] and Bekkouche [4]. It affects cooling load mainly in such regions where the temperature is well above average temperatures of thermal comfort standards [7]. In addition to what Haase [8] has stated that climate and orientation can determine the amount of solar radiation that the surfaces of the building will be exposed to. Spanos [9] has stated that a well orientated building on a site could reduce the energy consumption of the building up to $20 \%$. This effect will have an influence on the building along its roof, west and eastern wall, as they are exposed to the sun at certain times and locations [6]. Raychaudhuri [10] has highlighted that the longer side of a building should be facing north and south; it should admit the desirable directions of wind to attract it into the building. Some researchers differ with this view including Hamdani [5]. Hamdani [5] compared the effectiveness of both orientation and thermal insulation in buildings and the findings suggest that that orientation has a limited impact on building performance, he further concluded that to achieve better result thermal insulation would be the appropriate method, required along with shading devices.

In order to improve the performance of the orientation, more advanced technique should be applied, particularly where the solar radiation is quite high and the means of orientation is not enough to reduce it to the extent of acceptability. A study conducted by Kontoleon [11] has stated that the use of vegetation in very hot nations with the concept of orientation can improve the poorly oriented walls performance and compensate for its passive design.

\subsection{Brief Literature Review}

Building form is an important factor in green building design because of its significant impact on energy performance and consumption [12]. Lomas [13] and Okeil [14] have stated that building shape has an important result on ventilation in buildings which will help to control air movement inside and around buildings. The form of the individual building is not enough to control the air movement around buildings, studying the surrounding urban area is also essential. This will help to understand the pattern of the air more clearly and hence to prevent it from getting into each building as it is required.

The study of AlAniz [15] has expressed the performance of the most basic and common shapes which are relative compactness of shape, window to wall ratio and glazing type. The experiment has been done on office buildings. The study has stated three main factors that affect building shape where the buildings are standing very close from each other in a compact way. For instance, reducing the air speed around these buildings. The other factor that has an impact on building shape is the window-to-wall ratio and finally is the glazing type and total area which contribute to the total cooling and heating load remarkably. This has been supported by [15] as he has contended that there is a strong correlation between building form and glazing. Self-shading is also another technique for obtaining energy saving by utilizing building form [16]. Building form is quite connected to building function which was investigated and reviewed by Alwetaishi [17].

Thermal insulation is one of the most effective methods of saving energy for building heating and cooling load Robert [18], Lollini [19], Kolaitis [20], Hanifi [21], Jinghua [22], Dimoudi [23], Comakli [24] and Mahlia [25], it is also an important way to achieve thermal comfort in winter and summer and it reduces any unwanted heat losses [26]. Omer [27] has pointed out that the density of the material used in thermal insulation is associated with thermal conductivity. Higher insulation density results in lower thermal conductivity (k-value) which means better performance of the insulation. Numerous studies have estimated the optimum thickness of thermal insulation in different climates. Moreover, they are considering both heating and cooling loads equally [27]. Bojic [28] has highlighted that the reduction in such load relies heavily on the thickness of the insulation.

Thickness of thermal insulation has a major impact on material performance [29], it will result in a decrease in the energy consumption for cooling and heating, however the cost will rise as well. As a result, there must be an optimum point where the efficiency and cost could meet together [22]. Muhammet [30] has revealed that the optimum material insulation thickness payback period might take on average approximately $10 \mathrm{y}$ depending on several elements such as climate conditions, construction of the external walls, and type of insulation and cost of energy.

Meral [31] has considered that the optimum orientation thickness in warm regions (case study for Antalya) for south, north, east and west are obtained as following 3.6, 3.1, 4.0 and $4.0 \mathrm{~cm}$, respectively. This indicates that east and west receive higher solar radiation than the rest. External thermal insulation is most commonly preferred and used as it offers a wide range of advantages, for example it offers a protection from moisture condensation, straightforward tackler of thermal bridges and utilization of thermal mass. On the other hand, this technique has a disadvantage which is the cost and difficulty of applying it to higher floors [20]. In contrast, Salah [32] believes that having the insulation material within the inner side of the external wall will bring the standard level of thermal comfort faster than having it within the outer surface. In fact, this might be the only other view which I came 
across in reviewing the position of thermal insulation as most of the published work supported the first view. As the current research is dealing with hot regions, a study done in Riyadh shows that thermal insulation of thickness of 5-10 cm located outside the wall gives the best result [32].

Thermal mass is the capability of the material to store heat (heat capacity), in summer all the exposed surfaces of walls and floors will start to absorb heat from the outer surface, and storing this heat until it gets cooler to begin to migrate back and eventually released. This mechanism will aid to maintain stabilised internal temperature which prevents overheat which may occur in summer periods. In winter the thermal mass can store the heat from the sun through the surface to release it at night when it gets cooler. In addition, the heat gained from direct sunlight can help to raise the indoor air temperature passively which reduces heating load [33]. The usage of thermal mass can reduces the peak heat or cooling in buildings, one of the most important aspects of its features is the thermal storage capacity which describes the ability of thermal performance of the material [34]. In hot aired locations it is highly advised to use thermal mass to allow the internal condition to be smoother than large outdoor fluctuated temperature Eduardo [35] and Roberto [18].

\subsection{Effect of Window System}

Glazing within windows is usually a thermally weak system and responsible for a large amount of heat loss and gains that could have an impact on the entire energy consumption Roberto [18], Tsikaloudaki [36]. In addition, it is considered as the fragile link between the indoor and outdoor environments. In the case of heating, windows are responsible for $10-25 \%$ of heat loss, and in the case of cooling heat penetrating glass may lead to excessive heat gain depending on the outdoor temperature [37]. The importance and significance of glazing is not only limited to that extend to be weaker than opaque construction materials, it can also determine the amount of admitted solar gain as well as using it as mean for providing ventilation. This may include studying the effect of heat transmittance, direct solar gain and thermal bridging through glazing Abdullatif [38].

For such explanations, windows and glazing are of prime importance in modelling buildings to account for thermal comfort and over all energy consumption [39]. Consequently a considerable amount of energy can be saved by applying such technique into glazing systems [28].

\subsection{Window to Wall Ratio}

The window to wall ratio area has important impact on energy saving for heating and cooling in buildings. This effect is determined on the type of glazing since the glazing has a greater effect than Hollow glazing or even low-Hollow. Solar heat gain will increase as window to wall ratio increases, and also heat exchange will increase for heat transfer coefficient as windows have a larger area than sold wall [40]. Changing the window area would have a greater impact on building performance than changing the thickness of the external wall, [41-42] has added that not only the size but also the orientation has a large effect on windows which will determine the amount of transmitted and gained heat. However, all windows in each direction should be minimised in any warm and hot regions and the optimal window size varies depending on the location and its climate condition [43].

\subsection{Aim and Objectives of Study}

This research work is one of the few to deal with thermal comfort in Saudis' schools. This research is divided into three major parts. The first one is students thermal comfort levels within free running classrooms in the city of Jeddah. Secondly stage is to study the impact of fabric on the level of thermal comfort and indoor conditions. In the latter aim, four main elements are going to be addressed. These are as follows; orientation, glazing ratio, location in terms of outdoor exposure. In addition, the impact of thermal

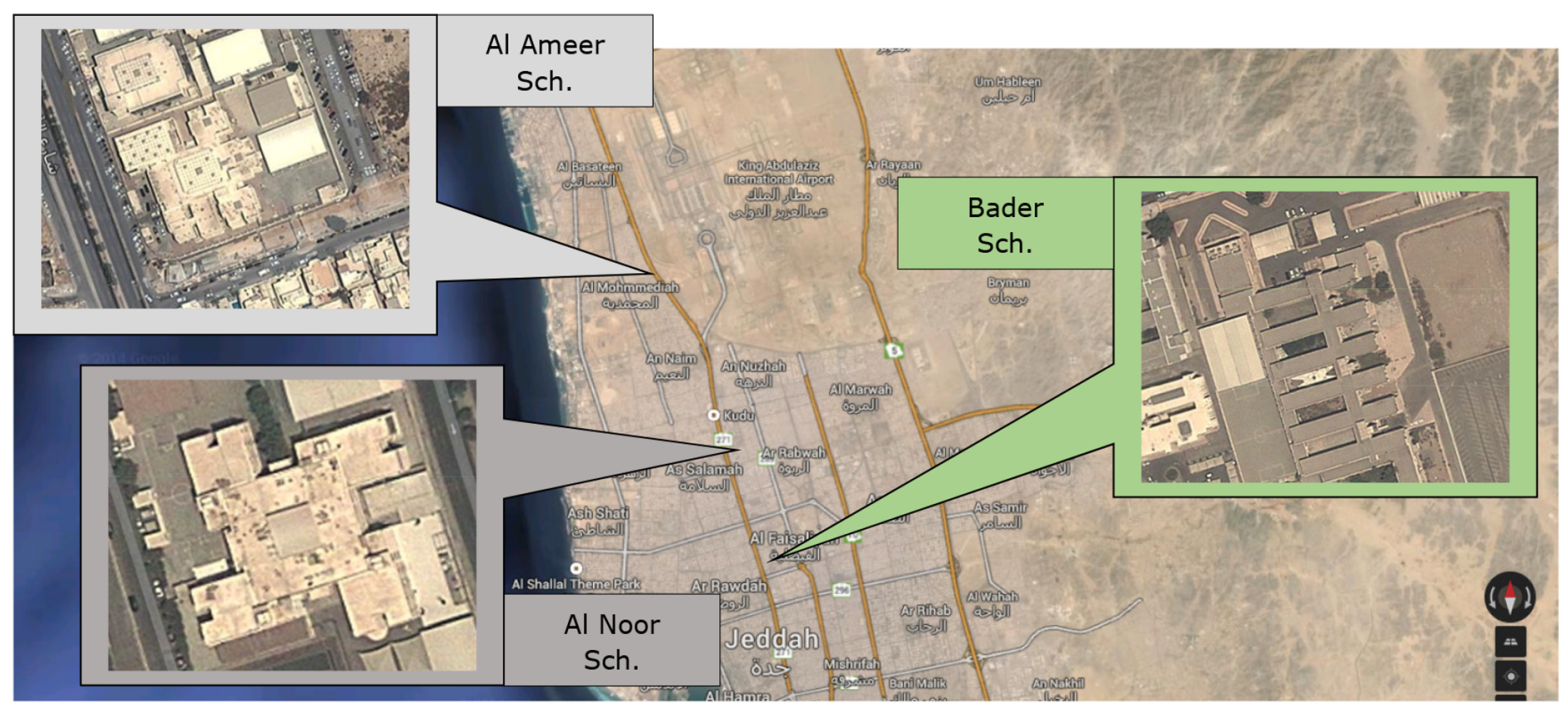

Fig. 2. Location of the case studies: All of them been chosen in Northern part of the city of Jeddah. Source: Google Map. 
mass and insulation are going to be analysed.

The aim of this research is to evaluate the indoor environment of school buildings in terms of several aspects such as the thermal comfort of students in school buildings and its relationship with fabric specification of building. The objectives of this study are:

- To understand the climate condition of Jeddah and its impact on school buildings.

- To provide a detailed description of selected school building design with respect to old and new generation.

- To provide a literature review on human thermal comfort and building performance.

- To assess the current indoor environmental quality of school buildings and students satisfaction.

- To identify the effectiveness of fabrics on school buildings in terms of thermal comfort and internal conditions.

\subsection{Significance of Study}

School building design in Saudi Arabia is in the form of prototype school building design (PSBD). This requires full consideration as any error in the design stage will lead to considerable amount of discomfort in association with waste in energy use. The research uses advanced equipment which is not restricted to indoor air temperature, but it is rather extended to measure all surfaces inside classrooms such as floor, roof and external walls, this will provide more accurate and comparable results. The research aims to enhance the investigation of indoor energy building performance using advanced and professional tools in various climate regions worldwide.

\section{Materials and Methods}

\subsection{Materials}

Professional TECPEL Hot Wire Anemometer, the hot wire anemometer for very low air velocity measurement comes with RS 232 PC serial interface. It has multi-function for air flow measurement $(\mathrm{m} / \mathrm{s}, \mathrm{km} / \mathrm{h}, \mathrm{ft} / \mathrm{min}$, knots, and mile/h). The portable anemometer provides fast and accurate reading and also the convenience of a remote probe separately. It has a combination of hot wire and standard thermistors which deliver rapid and precise measurements even at low air velocity values. It comes with large LCD and dual function meter display where it can read the temperature and velocity at the same time. It has also some functions such as recording max and min readings, recall function, auto power off to same battery life and optional PC software. The second tool is the Professional CEM Dual Laser Infrared Thermometer. This compact infrared thermometer with dual laser provides fast and accurate non-contact for wide range measurement of surface temperature. It is quite useful to measure temperature even at unreachable surfaces. It has a quite wide range of temperatures $\left(-50^{\circ} \mathrm{C}\right.$ to $\left.450^{\circ} \mathrm{C}\right)$. In addition to that it can measure temperatures in ${ }^{\circ} \mathrm{C}$ as well as ${ }^{\circ} \mathrm{F}$. The response of the measurement is super-fast to provide measurement in less than 150 milliseconds.

CEM USB Temperature and Humidity Data logger tool allows monitoring of temperature and humidity values efficiently and conveniently for long time periods. It also saves the data and simply can be readable on your PC with a USB interface. The memory can save up to 32,700 readings which can last for many days. Moreover, it has the possibility of freely selectable measurement cycles from $2 \mathrm{~s}$ to $24 \mathrm{~h}$. Battery life makes it easier to use the device more effectively with a life of more than $3 \mathrm{y}$. In the second field trip, five CEM USB Temperature and Humidity Data loggers were used to measure temperature in more classrooms and in less time. Globe Thermometer which can be used to measure globe temperature (radiant temperature) were also used, it consists of a 6-inch-diameter hollow copper sphere which is painted with a matte black in order to observe the radiant heat from surrounding objects. The other part of this tool is a thermometer inserted through a rubber stopper which provides the temperature from $0^{\circ} \mathrm{C}$ to $100^{\circ} \mathrm{C}$. The model is supplied with a heavy stand and a mounting support to carry the devices. TECPEL External THERMO Hygrometer with external sensor was used to measure the internal and external temperature and relative humidity. It has two rows in a large digital LCD display indoor and outdoor measurement with temperature sensor. It has the features of providing max and min temperatures recorded and also records functions within internal clock $-10^{\circ} \mathrm{C}$ to $50^{\circ} \mathrm{C}$ is the range of this tool to measure for indoors whereas $-50^{\circ} \mathrm{C}$ to $70^{\circ} \mathrm{C}$ is the range for outdoors. It can measure humidity in the range of 20 to $99 \%$.

\subsection{Methods}

The use of equipment to measure the environmental parameters was also another major method in this research. The research measures indoor dry bulb temperature, outdoor dry bulb temperature, indoor relative humidity, outdoor relative humidity, indoor air velocity, outdoor air velocity, indoor globe temperature and temperature of internal inner surfaces for the selected classrooms. The tools used in the experiment for monitoring are presented in Fig. 3. There were three main intervals for measurement 5 a.m., 11 a.m. and 2:00 p.m. The reason for these periods is to ensure the time of min and max temperatures which represent the extremes of the outdoor condition and its influence on the internal status. In addition, the time specified of 11am was the only time of conducting the survey. Consequently, it was essential also to look at the internal conditions in order to compare the two results. There was an issue regarding the accuracy of the measurements taken and the use of AC system. This problem was solved at the time of 5 a.m. and 2 p.m. since all the classrooms are unoccupied, hence, there was no need for cooling load. However, an issue has been revealed at the time of conducting the survey (11 a.m.). As has been mentioned before, it was not possible to turn off the AC system all day as the schools rely heavily on the cooling system due to the harsh condition outdoors as well as the poor design of the new prototype school building, which has no consideration for any environmental design. This has contributed to unacceptable internal conditions even in winter. It was quite important for the research to obtain the same results derived from two different methods. This is why it was not possible to conduct the study at the weekends. However, weekends where used to set up data loggers only in order to investigate the pattern of $24 \mathrm{~h}$ in the complete absence of AC system for as many of the classrooms in the schools as possible. 
a

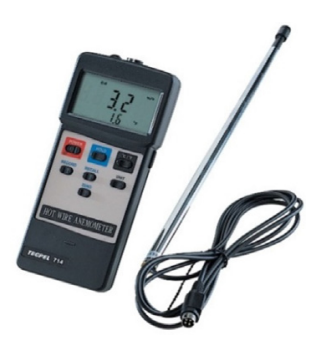

b

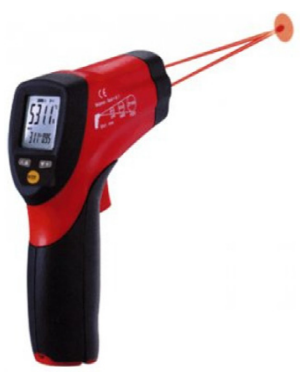

c

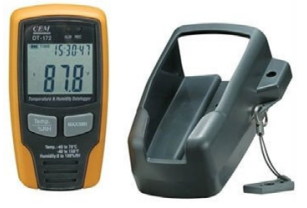

(a)

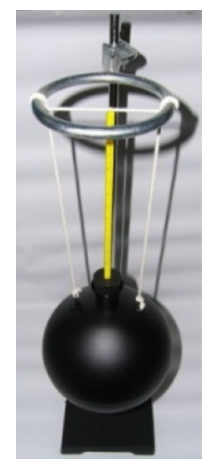

e

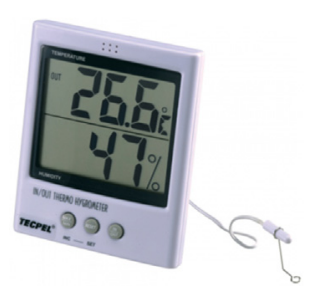

Fig. 3. Tools used in the experiment for monitoring, where:

a) Photos of the TECPEL Hot Wire Anemometer to measure indoor air velocity

b) CEM Dual Laser Infrared Thermometer to measure surface temperature from distance

c) CEM USB Temperature and Humidity Data logger to measure indoor temperature and humidity

d) Globe thermometer to measure globe temperature

e) Tecpel thermo hygrometer to measure outdoor temperature by sensor.

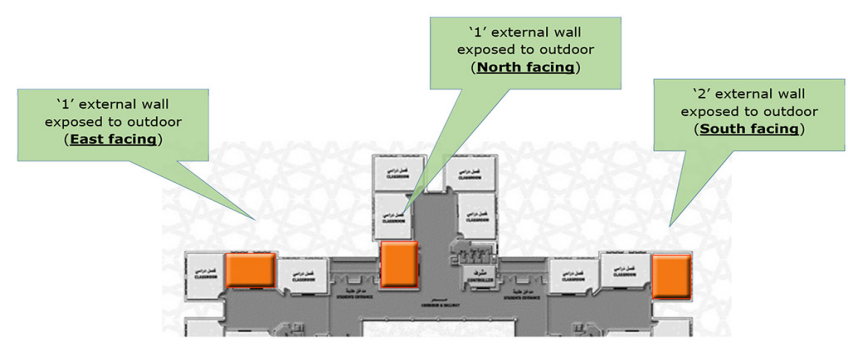

Top floor classroom [1_2]

First floor classroom [2_2]

Ground floor classroom [3_2]

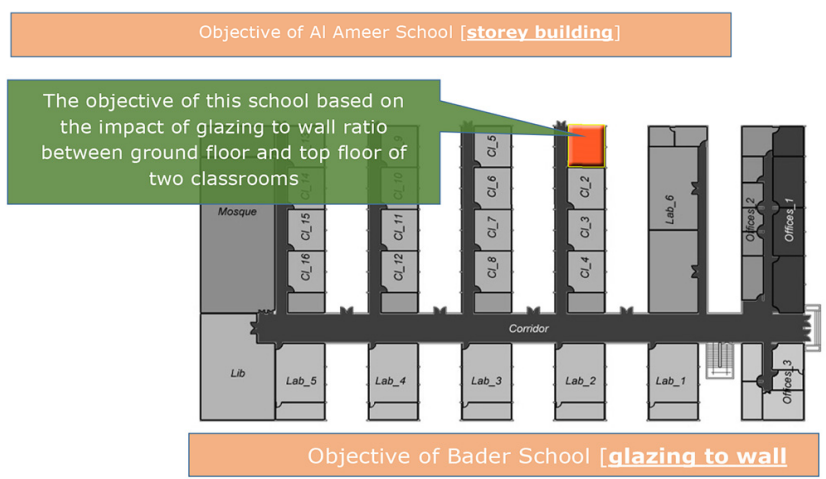

Fig. 4. Maps of the selected schools. Source: Ministry of education. Available online from: http://essamb.esy.es/moe/ARAB/PACES/ MAIN/news3.htm.

\section{Results and Discussion}

\subsection{Environmental Internal Condition (Monitored), in Al Ameer School}

Indoor, Outdoor, Floor Inner Surface, Roof Inner Surface Temperatures

The use of AC system at the selected classrooms makes it difficult for the surfaces to act naturally and freely. Generally, it can be observed that all the classrooms have a similar pattern in all the variables.

Outdoor air temperature (OAT) is the only variable that is constantly increasing during the day time $25^{\circ} \mathrm{C}$ as min at 5:00 a.m. and peak at $30^{\circ} \mathrm{C}$ or above later in the afternoon. In terms of winter results, indoor air temperature (IAT) performed with lower figures that later during the day when it should be higher due to the increase in OAT. Thus, it was not the case due to the use of AC system which is turned on around 5:30 a.m. in order to push the IAT up to provide thermally acceptable indoor environment for the arrival of the students. Classrooms 2 5 east-facing and 2_3 north-facing had generally lower IAT compared with classroom $3 \_3$ which is facing south $2-3^{\circ} \mathrm{C}$, particularly early in the morning and later during the afternoon since the use of $\mathrm{AC}$ at these times is limited or even completely absent.

As far as globe temperatures are concerned, there is a strong correlation between IAT and globe temperatures. This connection supports the results of IAT which indicate the increase of class 3_3 which is facing south. As the external wall is facing south with lower sun angle, a large quantity of heat is being transferred during the day time which is then released during the night which helps to preserves the internal conditions. The results show that GT of class 3_3 was $3^{\circ} \mathrm{C}$ higher than the other two classrooms; the source of this heat is from the stored energy in the fabric of the external fabric of the classroom. Furthermore, the variations between classrooms in GT are not clear in the other time experiment intervals due to the use of AC systems. Regarding floor inner surface 


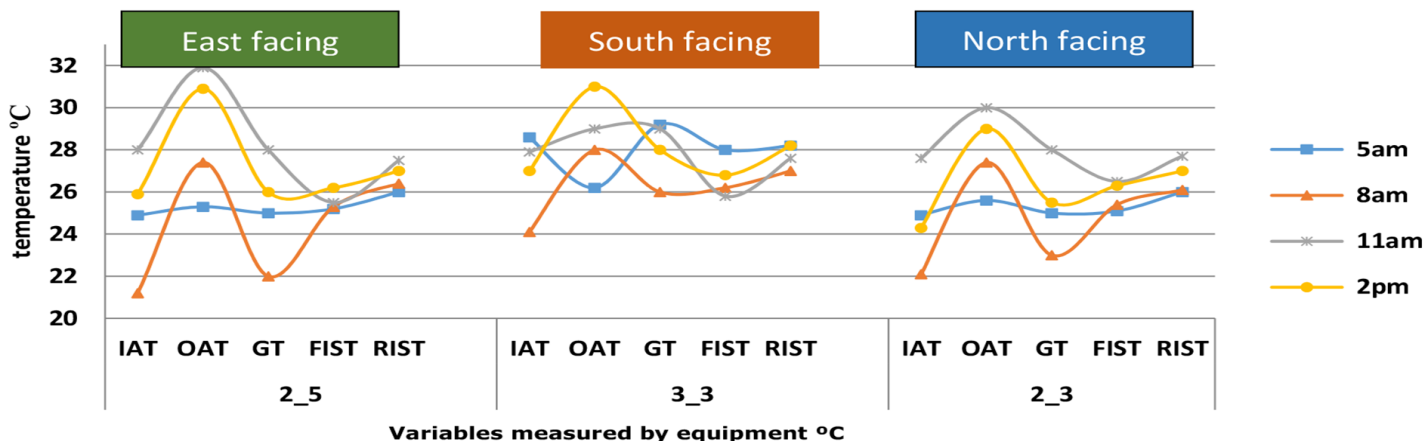

Fig. 5. Indoor, outdoor, globe, floor inner surface and roof inner surface temperatures of Al Ameer classrooms in winter.

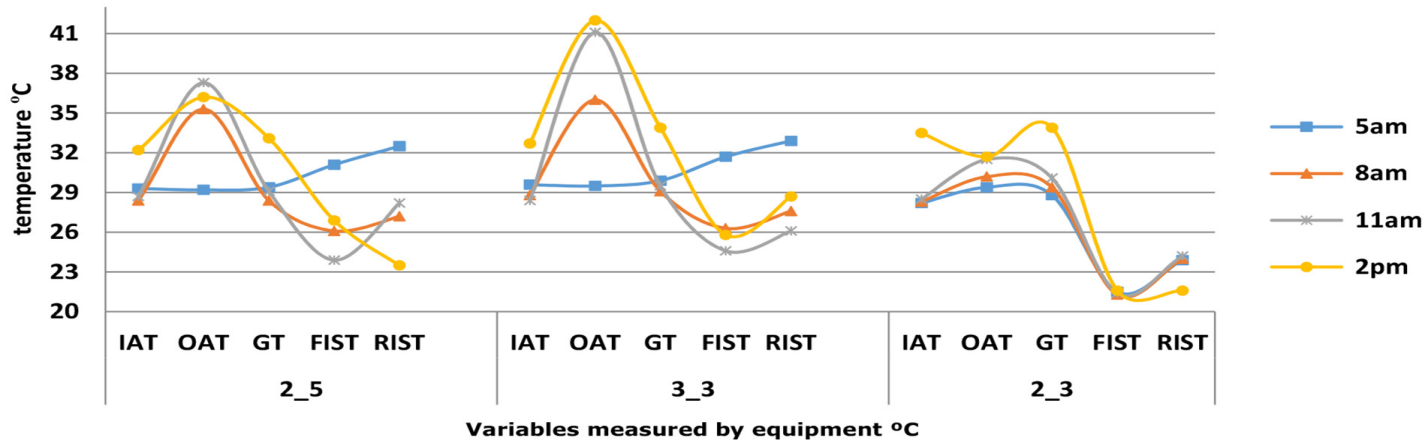

Fig. 6. Indoor, outdoor, globe, floor inner surface and roof inner surface temperatures of Al Ameer classrooms in summer.

temperature (FIST) and roof inner surface temperature (RIST), these measurements are mostly connected to IAT and OAT as it is exposed to outdoors. A constant increase was recorded regardless of the internal temperatures vacillation. Generally, it can be declared that both north and east facing classrooms have a similar microclimate performance based on the results derived from the above measurements while the south facing classroom is the only one which confirms the influence of various orientations.

In terms of the East facing block, $3 \mathrm{~T} 44$ and $3 \mathrm{~T} 3$ were the worse with higher IAT than 3 _ ${ }_{-} 2$ for two reasons. The first one

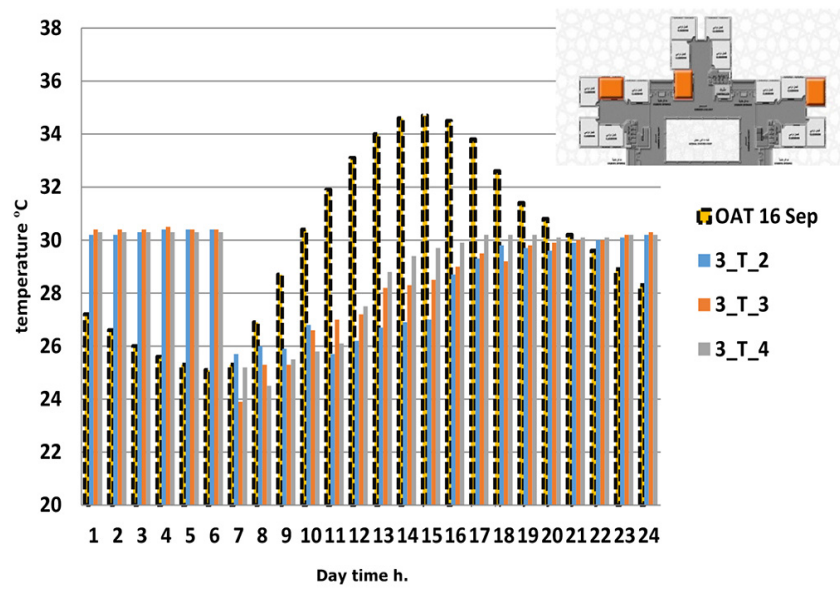

Fig. 7. SUMMER Indoor air temp IAT of East block classrooms in Al Ameer School, recorded by Data-logger in the same day $\left({ }^{\circ} \mathrm{C}\right)$.
Table 1. Summary Findings of IAT of Various Blocks of Al Ameer School with Respect to Various Orientations

\section{East block of Al Ameer classrooms}

C3_T_2 Lowest IAT due to single external wall

C3_T_3 Higher IAT than 3_T_2 due to double external (South and East) walls

C3_T_4 The highest IAT due to double external wall, (East and North) and face of windows

\begin{tabular}{cl}
\hline & South block of Al Ameer classrooms \\
\hline B_1 & The difference between the two classrooms \\
(West) & in terms of IAT is minor, but the results support \\
B_4 & the investigation in CH8 that west facing has \\
(East) & slightly higher IAT than east \\
\hline
\end{tabular}

is the double external walls exposed to outdoor and also the orientation. Moreover, classroom 3_T_4 had slightly higher indoor temperature than $3 \mathrm{~T} 3$ and this is because of the facing glazing of the later which is facing south whereas the first one facing east.

\subsection{Microclimate of Al Noor School}

Indoor, Outdoor, Floor Inner Surface Temperature and Roof Inner Surface Temperature

In this school, the main variable is the variation in levels (ground, first and top floor), where all the classrooms are facing south. The use of AC systems in the classrooms makes it quite complex 
to analyse the internal condition properly. Thus, utilising the absence of it during the experiment and out of school times might aid in the discussion and analysis. Regarding the winter results for the microclimate of the selected classrooms, the top floor (1_2) has a higher IAT by $2^{\circ} \mathrm{C}$ at 11 a.m. compared with the other two classrooms. This indicates the effect of heat conducted by the roof which is exposed to the outdoors. Similarly, globe temperature in the top classroom is the only zone where a gradual increase was recorded throughout the day, whereas in the other two a gradual decrease was reported. This might be due to radiation source of heat through the external wall including the window system. With regard to FIST, it was relatively higher in the ground floor class (3_2), which is expected as ground heat is the main source in this situation.

RIST was higher in classroom 1_2 which is located in top floor, and the source of heat is obvious. However, there are some uncontrolled variations between the classrooms in some variables such as RIST; this has a correlation with the circulated cool air generated by the AC. Consequently, unexpected figures were recorded. For instance, although the IATs of classrooms 2_2 and 3_2 are similar, the RIST was not. The only effect factor here is the influence of the AC system which varies in efficiency and duration of operation.

As far as the summer results are concerned, it has to be highlighted first that the OAT on the day of conducting 1_2 was considerably lower than 2_2 and 3_2. In addition to that it was partly cloudy

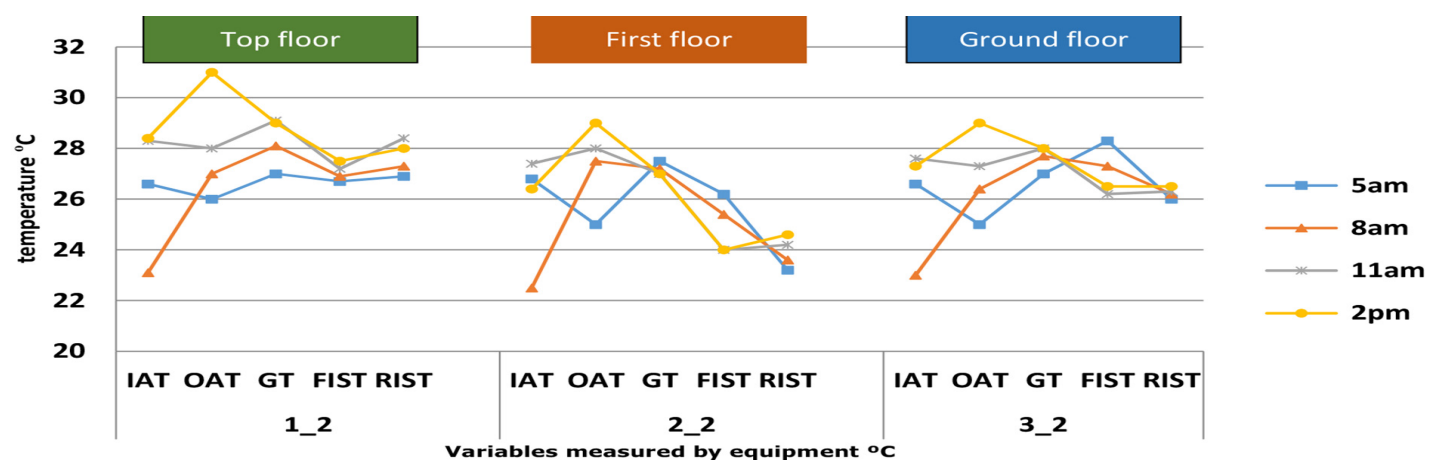

Fig. 8. Indoor, outdoor, globe, floor inner surface and roof inner surface temperatures of $\mathrm{Al}$ Ameer classrooms in winter.

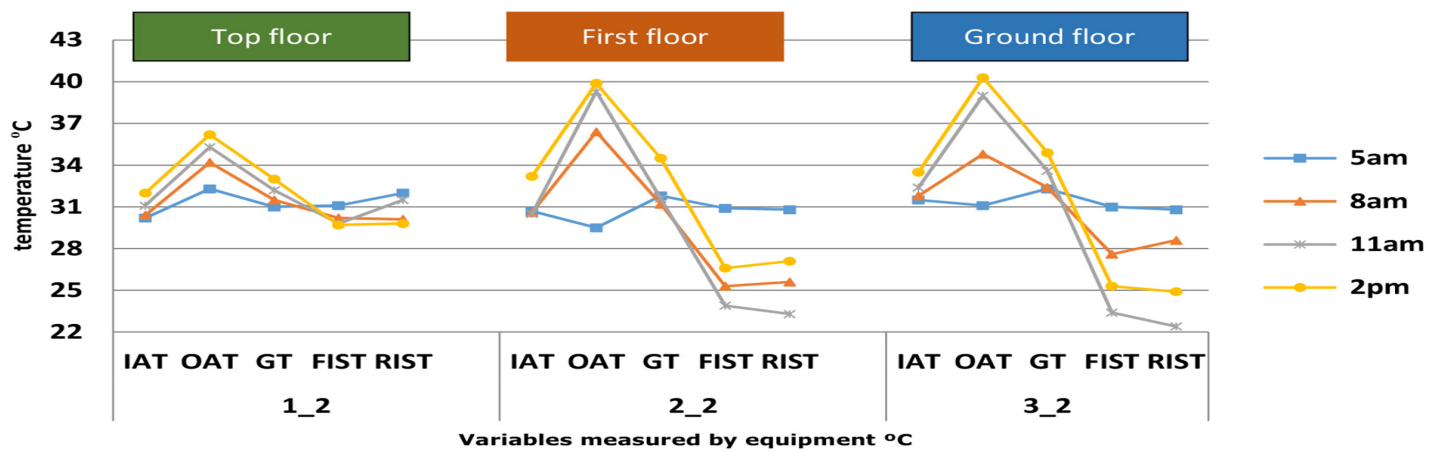

Fig. 9. Indoor, outdoor, globe, floor inner surface and roof inner surface temperatures of Al Ameer classrooms in summer.
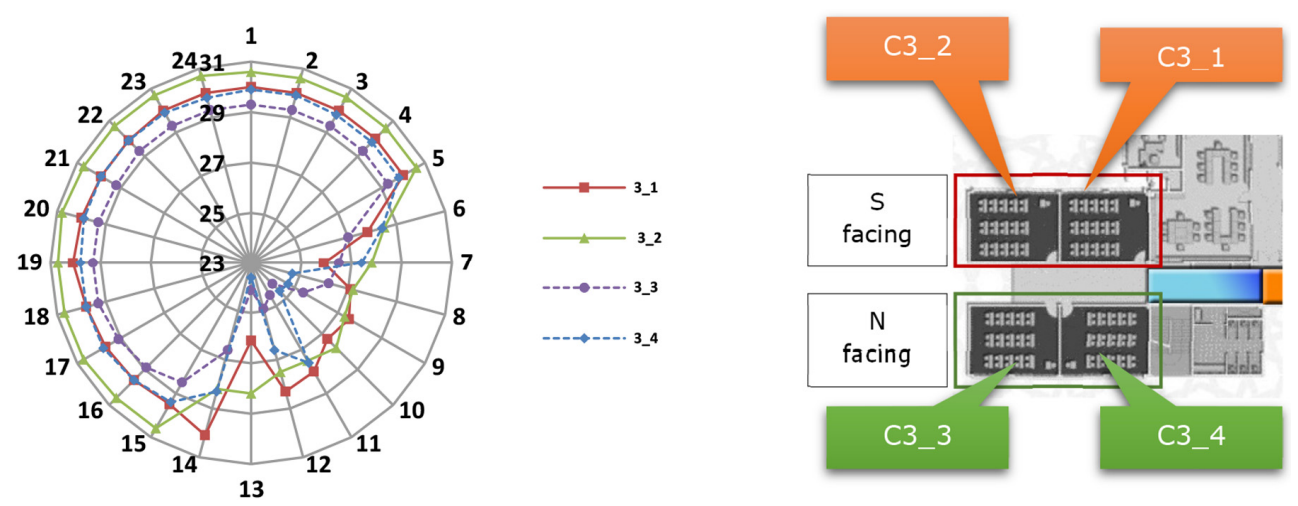

Fig. 10. Indoor air temperature of TOP floor classrooms Monitored from Data-logger in same day on $11 \mathrm{Sep},{ }^{\circ} \mathrm{C}$. 
day which will have an effect on solar radiation. However, taking into account all of these surrounding conditions, the top zone (1_2) remains the highest IAT.

\subsection{Dry Bulb Temperature of Al Noor Selected Classrooms in Both Summer and Winter}

The aim was to investigate the effect of various levels (storeys), it can be noted that the top floor has higher IATs than the other two classrooms, with certain variations. However, this variation is similar both in winter and summer $2-3^{\circ} \mathrm{C}$. The illustration for this might be the multiplicity of heat conduction sources for the top classroom where two main sources can be introduced. This first one is from the external wall which all the classrooms have; and secondly the ceiling is the additional source of heat conduction that would definitely, have an impact on IAT.

Considering the OAT in winter, it is clear that there was not any utilisation of natural ventilation. The min and max indoor temperatures are well above the outdoors. This distinctly indicates the level of thermal conditions indoors which, perhaps, will have its influence on thermal sensation. Moreover, the ground floor indoor temperature was quite identical with the first storey in winter. However, in summer there was a slight difference with about $2.5^{\circ} \mathrm{C}$ increase in the ground floor one. This might be owing to the ground temperature in summer which is expected to be higher than in winter. It is likely that this could have had an impact on the exposed classroom by conduction. It has been ac- knowledged that there is a strong correlation between an increase in indoor temperature and an increase in glazing ratio. In addition the top zones which have the ceilings as an extra surface exposed to outdoors, could lead to a $2-3^{\circ} \mathrm{C}$ rise in temperature in both winter and summer. Finally, the impact of ground located zones has higher effect in summer than in winter. This is due to the general increase in ground temperature which leads to heat transfer by conduction through its ground.

\subsection{Investigation of Surface Temperatures Performance on Different Directions Based on Jeddah's Climate in Both Winter and Summer}

In order to understand the influence of solar radiation on different surfaces orientations, this investigation has been conducted. To ensure an accurate result, the effecting variables have been controlled, such as location, day and time and colour of surface. The experiment has been conducted in one of the schools (Al Noor School) for 12 h, from 6 a.m. until 6 p.m. in both summer and winter. However, for some reasons it would not be possible to conduct the experiment for $12 \mathrm{~h}$ in winter, however, a prediction of the pattern of temperature was observed based on the actual summer performance. However, in terms of south facing performance, it can be noted that the increase of temperature in winter is greater during the morning than in the summer. Thus, the peak of the two (Fig. 11) was quite similar with only one degree difference. The effectiveness on the rest of the directions was more obvious
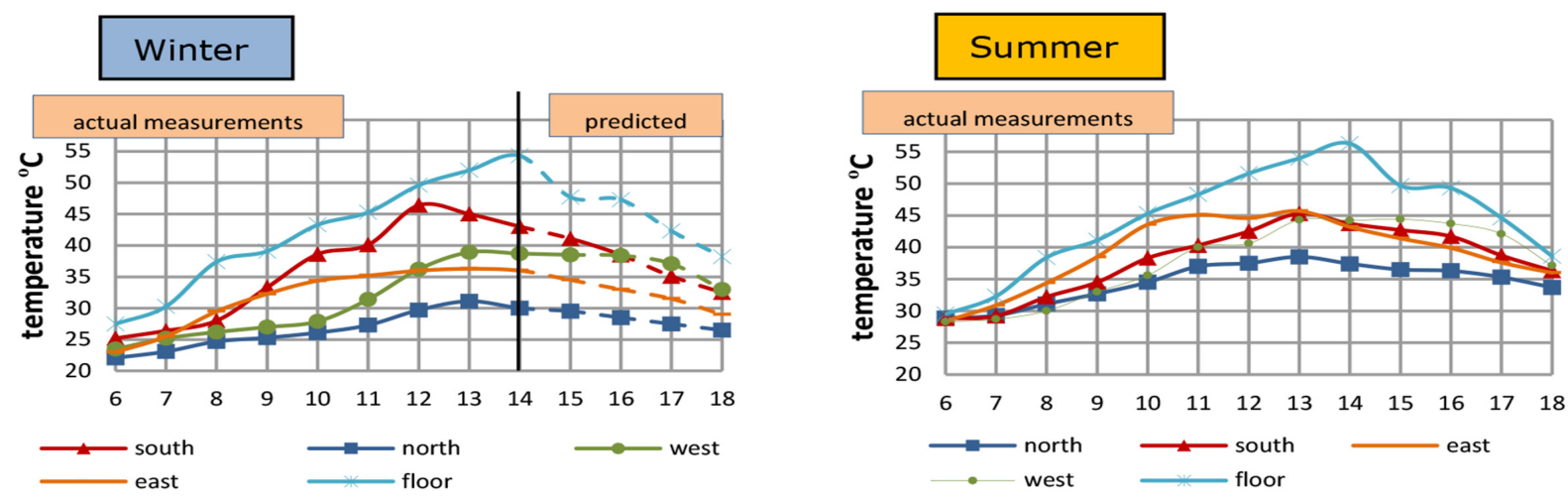

Fig. 11. Actual and predicted temperatures of surfaces on different directions in winter and summer, ${ }^{\circ} \mathrm{C}$.
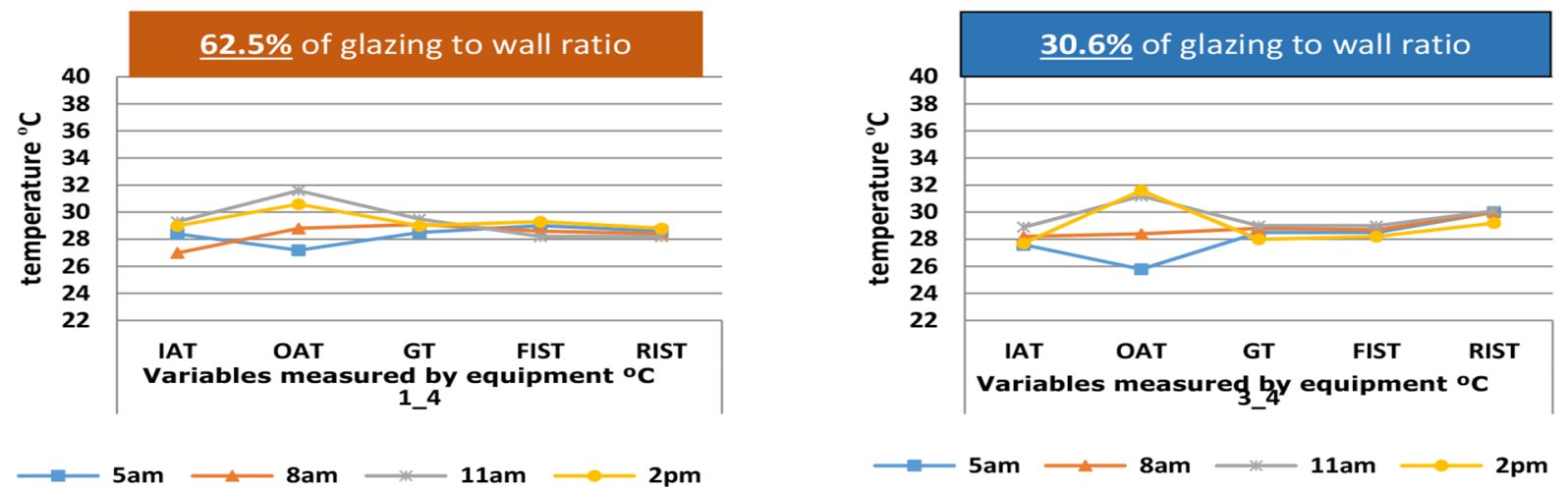

Fig. 12. Indoor, outdoor, globe, floor inner surface and roof inner surface temperatures of Bader School in winter. 

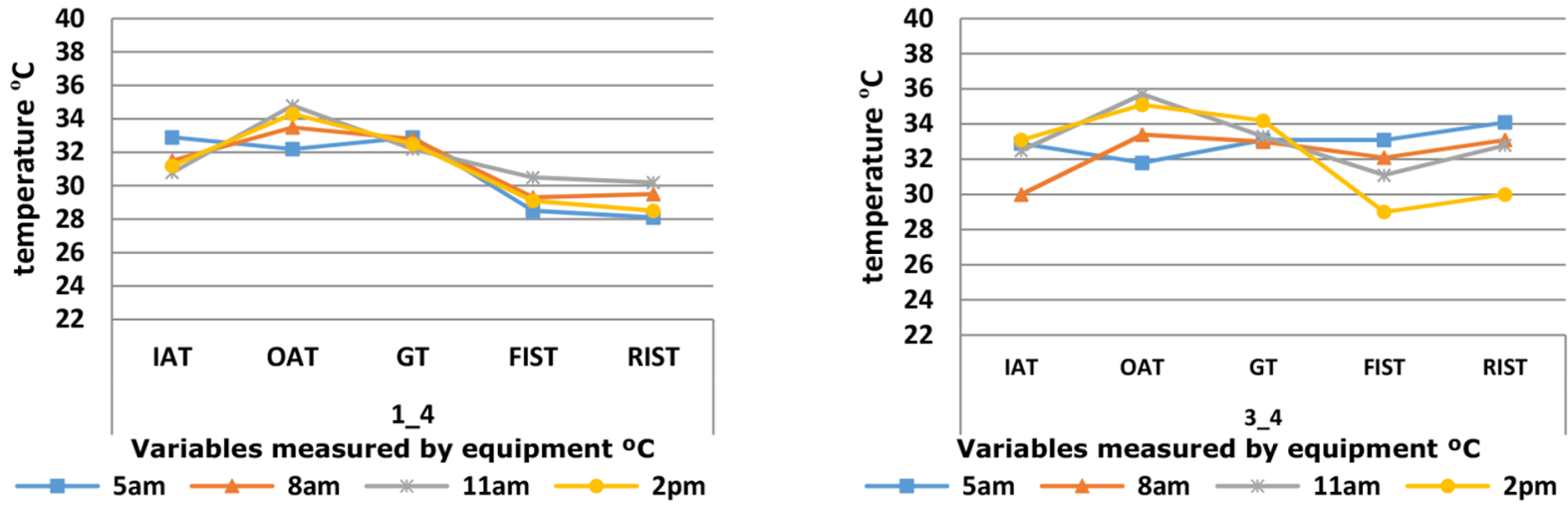

Fig. 13. Indoor, outdoor, globe, floor inner surface and roof inner surface temperatures of Bader School in summer.

'Rushan' which is a traditional aspect used previously in the old city of Jeddah, it is mainly used for the purpose of natural vent as well as blocking the direct sunlight
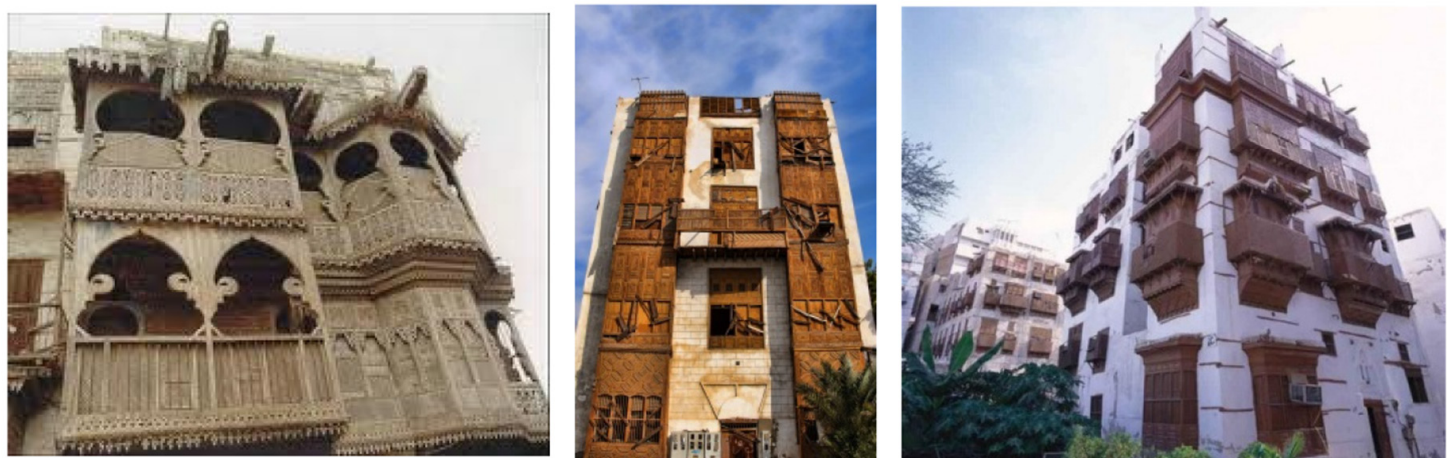

Fig. 14. Rushan of old city of Jeddah. Source: Sharq Al Ausat paper, available from: http://www.aawsat.com/.

difference of about $5^{\circ} \mathrm{C}$ was recorded for each direction of the later. The impact of solar radiation is greater only on the south facades in winter.

\subsection{Microclimate of Bader School}

Indoor, Outdoor, Floor Inner Surface and Roof Inner Surface Temperatures

The first indication raised from experience at this school is the naturally running system. Even though there was an AC system as in all other schools, this school also relies on non-technical means such as fans and the utilisation of natural ventilation. Furthermore, the efficiency and type of AC system is not as good as in the other school. On first impression, it seems that there are no major differences between the two classrooms regardless of the glazing ration. In terms of OAT, these were quite similar on the experiment days. As a result, a more detail comparison was observed. With regard to IAT, it is the only school, where a strong correlation was found between IAT and OAT.

This supports the view of identifying this school as a naturally running system, where it depends on natural ventilation and fans in achieving thermal comfort rather than AC. Globe temperature is similar in both zones; this is attributed to the orientation of both classrooms which controls the amount of direct solar gain through 1_4 class which has a huge glazing system. It can be declared that in hot and humid climates having a large area of glazing would improve the indoor environment in terms of daylight and natural ventilation, and at the same time can control the amount of solar gain through glazing. However, they have to be facing north to avoid direct solar gain; otherwise shading devices have to be applied.

RIST was higher in classroom 3_4 by 1.5 to $2^{\circ} \mathrm{C}$ which is understandable due to the exposure of this classroom to the outdoors through its ceiling. As this might be an issue, the two classrooms have two sides exposed to outdoors, one of them is facing outdoor through its ceiling (3_4), and the other by an external wall facing east. Based on the previous experiments conducted in $\mathrm{Al}$ Noor and $\mathrm{Al}$ Ameer Schools, an acceptable comparison can be applied as the effect of distinct variables is inconsequential. In terms of summer results, as in winter IAT and OAT were quite analogues. This also expresses that even in summer there is a strong connection between indoors and outdoors through the exploitation of natural ventilation. The average IAT in both classrooms was $31^{\circ} \mathrm{C}$, and so was the GT. However, RIST in the top floor was higher than on the ground floor by an average of $3^{\circ} \mathrm{C}$ which is acceptable as 
the later has its roof as an internal construction marital. It can be said that providing a larger area of glazing facing north has more advantages than disadvantages depending on the ratio. Moreover, direct solar access is very limited since the temperature differences between outdoor actual and indoor preferable is quite limited. As a result, providing thermal comfort by increasing air velocity is quite essential.

\section{Conclusions}

Al Ameer School: The north and east facing classrooms have confirms microclimate conditions while the south one is the only which conform the influence of variations of orientation. In summer, generally there is a more noticeable variation in the IAT than in winter. Indoor surface temperature of external walls is a major issue in this school building as it aimed to study the impact of orientation. There is a variation of $3^{\circ} \mathrm{C}$ to $5^{\circ} \mathrm{C}$ caused by infiltration. Moreover, it is apparent that glazing ratio has the most effect on indoor thermal performance leading to a rise from $7-10^{\circ} \mathrm{C}$. Generally, the north-facing classroom has the best performance compared with the other, east and south-facing, classrooms. Al Noor School: There is a noticeable influence on the top classroom which has its roof exposed to the outdoors. This may cause a rise of $2-3^{\circ} \mathrm{C}$ in winter and summer. On the other hand, there is no significant impact of heat conducted through the ground floors on IAT. It has to be mentioned that there is a strong correlation between increase in indoor temperature and glazing ratio. The influence of external wall heat conduction ranks second after roof heat conduction; without taking into account the conducted heat through glazing. Finally, the impact of surface temperature is greater in winter on the southern façade; otherwise the impact of summer is dominant. Bader School: IAT of this school is quite similar to outdoor, which reflects its unique natural element. This was the result of the utilisation of natural ventilation and fans, with the aid of north-facing for all classrooms in the school. It has to be mentioned that a larger area of glazing blocked from direct sunlight has a better influence on indoor condition and general thermal sensation. As the total area of glazing of classroom 1_4 comprises $62.5 \%$ of its external wall, whereas the one in classroom 3_4 is only $30.6 \%$, the later has much lower solar gain which is even less than half the amount of the ground floor classroom. Possible future application can be conducted on more School building design as this research was focused on only three of them. In addition to that, climatic responsive can be also another factor to consider. This investigation was restricted to the case study location which is hot-humid. This research is beneficial at many points and views. First of all, since the school building design in the country is based on prototype design, the findings of the research can be used in order to develop these schools for future plan construction. The country will contribute to raise the awareness of sustainable building design on the scale of the industry based on the large number of schools construction. In addition, this will aid to provide more thermally acceptable indoor environment for students which will encourage them to study and gain knowledge.

\section{Acknowledgments}

The authors would like to thank the ministry of education for their support in conducting the research. They have provided us with official letters sent to the schools selected which helped us significantly. The authors also would like to express their special thanks to the head of each school of (Al Ameer, Al Noor and Bader Schools) for their assistance and support taking the measurement and filling in the surveys by the students.

\section{References}

1. Sojobi AO, Balogun II, Salami AW. Climate change in Lagos state, Nigeria: What really changed? Environ. Monit. Assess. 2016;188:1-42.

2. Deng JY, Wong NH, Zheng X. The study of the effects of building arrangement on microclimate and energy demand of CBD in Nanjing, China. Procedia Eng. 2016;169:44-54.

3. Morrissey J, Moore T, Horne R. Affordable passive solar design in a temperate climate: An experiment in residential building orientation. Renew. Energ. 2001;36:568-577.

4. Bekkouche SMA, Benouaz T, Yaiche MR, Cherier MK, Hamadani $\mathrm{M}$, Chellali F. Introduction to control of solar gain and internal temperatures by thermal insulation, proper orientation and eaves. Energ. Buildings 2011;43:2414-2421.

5. Hamdani M, Benouaz T, Cherier M. Study and effect of orientation two room of buildings located in Ghardaïa, Algeria. Energy Procedia 2012;18:632-639.

6. Assem E. Correlating thermal transmittance limits of walls and roofs to orientation and solar absorption. Energ. Buildings 2011;43:3173-3180.

7. Kruger E, Pearlmutter D, Rasia F. Evaluating the impact of canyon geometry and orientation on cooling loads in a high-mass building in a hot dry environment. Appl. Energ. 2010;87: 2068-2078.

8. Haase M, Amato A. An investigation of the potential for natural ventilation and building orientation to achieve thermal comfort in warm and humid climates. Sol. Energy 2009;83:389-399.

9. Spanos I, Simons M, Holmes KL. Cost savings by application of passive solar heating. Struct. Survey 2005;23:111-130.

10. Raychaudhuri BC, Ali S, Garg DP. Indoor climate residential buildings in hot arid regions: Effect of orientation. Build. Sci. 1965;1:79-88.

11. Kontoleon K, Bikas D. The effect of south wall's outdoor absorption coefficient on time lag, decrement factor and temperature variations. Energ. Buildings 2007;39:1011-1018.

12. Wang Z. A field study of the thermal comfort in residential buildings in Harbin. Build. Environ. 2006;41:1034-1039.

13. Lomas K. Architectural design of an advanced naturally ventilated building form. Energ. Buildings 2007;39:166-181.

14. Okeil A. A holistic approach to energy efficient building forms. Energ. Buildings 2010;42:1437-1444.

15. AlAnzi A, Seo D, Krati M. Impact of building shape on thermal performance of office buildings in Kuwait. Energ. Convers. Manage. 2009;50:822-828. 
16. Capeluto G. Energy performance of the self-shading building envelope. Energ. Buildings 2003;35:327-336.

17. Alwetaishi M. Impact of building function on thermal comfort: A review paper. Am. J. Eng. Appl. Sci. 2016;9:928-945.

18. Roberto F, Walter M, Marc A, Nathan M. Capacitive effect on the heat transfer through building glazing systems. Appl. Energ. 2011;88:4310-4319.

19. Lollini B, Fasanob M. Optimisation of opaque components of the building envelope. Energy, economic and environmental issues. Build. Environ. 2006;41:1001-1013.

20. Kolaitis D, Malliotakis E, Kontogeorgos D. Comparative assessment of internal and external thermal insulation systems for energy efficient retrofitting of residential buildings. Energ. Buildings 2013;64:123-131.

21. Hanifi B, Mustafa E, Mustafa D, Orhan A, Mehmet K. An environmentally friendly thermal insulation material from sunflower stalk, textile waste and stubble fibres. Constr. Build. Mater. 2014;51:24-33.

22. Jinghua Y, Changzhi Y, Liwei T, Dan L. A study on optimum insulation thicknesses of external walls in hot summer and cold winter zone of China. Appl. Energ. 2009;86:2520-2529.

23. Dimoudi A, Kostarela P. Energy monitoring and conservation potential in school buildings in the C' climatic zone of Greece. Renew. Energ. 2009;34:289-296.

24. Comaklı K, Yüksel B. Environmental impact of thermal insulation thickness in buildings. Appl. Therm. Eng. 2004;24: 933-940.

25. Mahlia T, Iqbal A. Cost benefits analysis and emission reductions of optimum thickness and air gaps for selected insulation materials for building walls in Maldives. Energy 2010;35:2242-2250.

26. Ashok K, Suman B. Experimental evaluation of insulation materials for walls and roofs and their impact on indoor thermal comfort under composite climate. Build. Environ. 2013;59: 635-643.

27. Omer K. A review of the economical and optimum thermal insulation thickness for building applications. Renew. Sust. Energ. Rev. 2012;16:415-425.

28. Bojic M, Yik F, Sat P. Influence of thermal insulation position in building envelope in the space cooling of high-rise residential building in Hong Kong. Energ. Buildings 2001;33:569-581.

29. Asan H, Sancaktar Y. Effect of wall's thermophysical properties on time lag and decrement factor. Energ. Buildings 1998;28: 159-166.
30. Muhammet K, Keçebas A, Gedik E. Determination of optimum insulation thickness of external walls with two different methods in cooling applications. Appl. Therm. Eng. 2013;50:217-224.

31. Meral O. Determination of optimum insulation thickness based on cooling transmission load for building walls in a hot climate. Energ. Convers. Manage. 2013;66:106-114.

32. Salah M. On the heat flow into the ground. Renew. Energ. 1999;18:473-490.

33. Chris R. Thermal mass your home [Internet]. Australia: Australian Government. c2013 [cited 18 February 2015]. Available from: http://www.yourhome.gov.au/passive-design/ thermal-mass.

34. Lina Y, Yuguo L. Cooling load reduction by using thermal and night ventilation. Energ. Buildings 2008;40:2052-2058.

35. Eduardo K, Eduardo G, Baruch G. Effectiveness of indirect evaporative cooling and thermal mass in a hot arid climate. Build. Environ. 2010;45:1422-1433.

36. Tsikaloudaki K, Theodosiou T, Bikas K. Assessing cooling energy performance of windows for residential buildings in the Mediterranean zone. Energ. Convers. Manage. 2012;64:335-343.

37. Kamal M, Greig N, Alhomid A, Al-Jafari A. Kinetics of human acetylcholinesterase inhibition by the novel experimental Alzheimer therapeutic agent, tolserine. Biochem. Pharmacol. 2000;60:561-570.

38. Abdullatif E. Minimizing thermal bridging through window systems in buildings of hot regions. Appl. Therm. Eng. 2002;22:989-998.

39. Pal S, Roy B, Neogi S. Heat transfer modelling on windows and glazing under the exposure of solar Radiation. Energ. Buildings 2009;41:654-661.

40. Xing S, Xu Z. Environmental performance optimization of window-wall ratio for different window type in hot summer and cold winter zone in China based on life cycle assessment. Energ. Buildings 2010;42:198-202.

41. Bouchlaghem N. Optimising the design of building envelopes for thermal performance. Automat. Constr. 2000;10:101-112.

42. Andrea G, Giovanni P, Francesca C. Analysis and modelling of window and glazing systems energy performance for a well-insulated residential building. Energ. Buildings 2011;43:1030-1037.

43. Lee J, Chio J. Influences of clothing types on metabolic, thermal and subjective responses in cool environment. J. Therm. Biol. 2004;29:221-229. 